\title{
Modeling and Analysis of Pitch Angle Control on Variable Speed Wind Turbines
}

\author{
Hasan Bektas Percin ${ }^{1+}$ (D) Abuzer Caliskan ${ }^{2}$ (D) \\ ${ }^{1 *}$ Firat University, Electrical, and Electronics Engineering Department, Elazig, Turkey. (e-mail: hbpercin@ firat.edu.tr). \\ ${ }^{2}$ Firat University, Electrical and Electronics Engineering Department, Elazig, Turkey. (e-mail: acaliskan @ firat.edu.tr).
}

\section{ARTICLE INFO}

Received: Nov., 09. 2020

Revised: Apr., 05. 2021

Accepted: May, 06. 2021

Keywords:

Wind energy

Modeling

Matlab/Simulink

Pitch angle

Permanent magnet synchronous generator

Corresponding author: Hasan Bektas

Percin

ISSN: 2536-5010 | e-ISSN: 2536-5134

DOI: https://doi.org/10.17694/ejt.823439

\section{ABSTRACT}

Nowadays, due to the increasing demand for electrical energy, investments in renewable energies are a satisfactory solution to meet this demand. Wind energy, which is one of these renewable energies, has many advantages such as low environmental impact, renewable structure, and decreasing system costs with developing technology. However, the instant changes of the wind, affect the sustainability of the system and the production efficiency negatively.

Maximum efficiency, stable and long-lasting operation is aimed at wind energy conversion systems with permanent magnet synchronous generators (PMSG). In line with these objectives, systems should be used with appropriate control structures. Modeling studies in the computer environment allow analyzing the different controls to be used in energy conversion, which can be difficult and costly to work on the real system. These studies provide analysis, comparison of various control parameters, and adjustments before system installation, Thus, the problems can be prevented before the installation, higher performance and less costly designs can be achieved.

In this study, the basic components and parameters of the wind energy system were explained and mathematical models of these parameters were obtained. The working principle of the control structures for the system was explained through these models. The general system modeling, which includes pitch angle control for higher wind speeds, was designed in Matlab/Simulink environment, and graphical analysis of the control structure was performed based on various system parameters. As a result, the control structure ensured stable operation of the system at higher wind speeds.

\section{INTRODUCTION}

Wind energy conversion systems (WECS), used to generate electrical energy, are structures created by the integration of mechanical and electrical components. Turbines and generators used in energy conversion are the most crucial parts of these systems. Commercially, three-bladed, speed and pitch angle-controlled turbines are commonly used. For generators, permanent magnet synchronous generators (PMSG) have come to the fore due to their characteristics such as direct connection to wind turbines, compatibility with variable speeds, and higher efficiency due to permanent magnets in their rotors. Different control methods are used for higher production efficiency, preventing mechanical and less electrical stress to the system and increasing the service life of the system. Before applying different control methods to the system, simulation of a WECS through a computer program such as Matlab/Simulink provides dynamic and steady-state performance of the system by selecting appropriate control methods and analyzing different system parameters. Thus, more efficient systems can be installed at lower costs.

In the literature, Different control simulations have been conducted based on the mathematical models of the system components. Furthermore, graphical analysis based on system parameters for different techniques is presented in [1-3]. In other studies; based on reference frame conversion, PMSG and electronic interface simulations are presented in [4-6]. There are many different studies on the analysis of the pitch angle control used for WECS in [7-10]. Comparative analysis of these control techniques allows appropriate control selection and design as presented in [11-14]. There are also studies using soft computing methods such as fuzzy logic and neural networks used for the pitch angle control in [11, 1518].

In this study, the main components of a WECS and its basic controls, such as maximum power point tracking (MPPT) and pitch angle control techniques were explained theoretically. Simulation of the system in Matlab-Simulink 
environment was carried out and system parameters were analyzed based on the pitch angle control.

\section{MATERIAL AND METHOD}

Figure 1 shows the main components of a WECS and energy conversion stages.

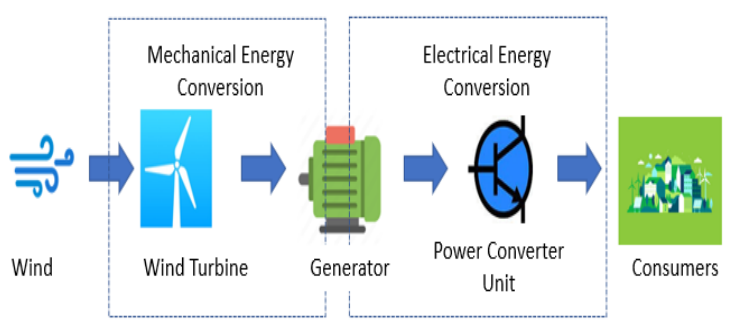

Figure 1. Basic conversion scheme for REDS

Criteria in the selection of WECS components are

- Size

- Design and Maintenance costs

- Control designs ensuring stable and efficient operation

The main objective for a WECS is to create a system where efficient and ergonomic components are used to design a control for high efficiency, according to instant winds. As for the working principle of the system, the kinetic energy of the wind is converted into mechanical energy by the wind turbine. Then, this energy is transferred to the generator through the drive system between the turbine and generator. Finally, produced electrical energy is supplied to the grid or a standalone load by the power converter unit, which is used as an intermediate link structure and used to control the efficiency and quality of the produced energy $[19,20]$.

In the earlier designs, 3-bladed fixed-speed turbines were commonly used. Due to the low efficiency and power quality of the fixed types, variable speed, pitch angle-controlled turbines with PMSG, whose rotor speed can be adjusted according to instant wind speed, have been widely used at present.

For a variable speed WECS, there are two main control structures. The first is to control the speed of the system below the rated wind speeds, the latter is to control the pitch angle of the turbine for protecting the system components above the rated wind speeds $[21,23]$. WECSs can be operated at wider range wind speeds without exceeding the rated power through pitch angle control.

Computer simulations can be used for selecting and designing proper control structures. For this purpose, Basic models of the system components are needed. These models explain the energy efficiency and conversion process.

\subsection{Wind turbine model}

The mechanical power transferred to the generator from the turbine is expressed as shown in Equation (1) [3, 24-26].

$$
P=\frac{1}{2} \times C_{P} \times p \times A \times V_{W}^{3}
$$

In this equation, $P$ is the power extracted from the wind (W), $p$ is the air density, which is equal to $1.225 \mathrm{~kg} / \mathrm{m}^{3}, C_{P}$ is the power coefficient, $V_{W}$ is the wind speed $(\mathrm{m} / \mathrm{s})$, and $A$ is the area swept by the rotor $\left(\mathrm{m}^{2}\right)$. The power coefficient, showing the ratio of power extracted from wind energy, can be defined based on two parameters as shown in Equation (2).

$$
C_{P}(\lambda, \beta)=C_{1}\left(\frac{C_{2}}{\lambda_{i}}-C_{3} \times \beta-C_{4}\right) e^{-\left(C_{5} / \lambda_{i}\right)}+C_{6} \times \lambda
$$

Coefficients $C_{1-6}$ are characteristic values for turbines. $\beta$ (pitch angle) is kept at a minimum value below the rated wind speeds, and it can be adjusted to prevent the turbine from damage especially at higher wind speeds. The tip speed ratio $\lambda$ and $\lambda \mathrm{i}$ parameters are defined as shown in Equation $(3,4)$.

$$
\begin{gathered}
\lambda=\frac{w \times R}{V} . \\
\frac{1}{\lambda_{i}}=\frac{1}{\lambda+0.08 \beta}-\frac{0.035}{\beta^{3}+1} .
\end{gathered}
$$

In Equation (3), $w$ is the angular velocity of the rotor $(\mathrm{rad} / \mathrm{s}), R$ is the rotor radius $(\mathrm{m})$ and $V$ is the wind speed $(\mathrm{m} / \mathrm{s})$.

Figure 2 shows the power coefficient $C_{P}$ as a function of the tip speed ratio $(\lambda)$ and pitch angle $(\beta)$.

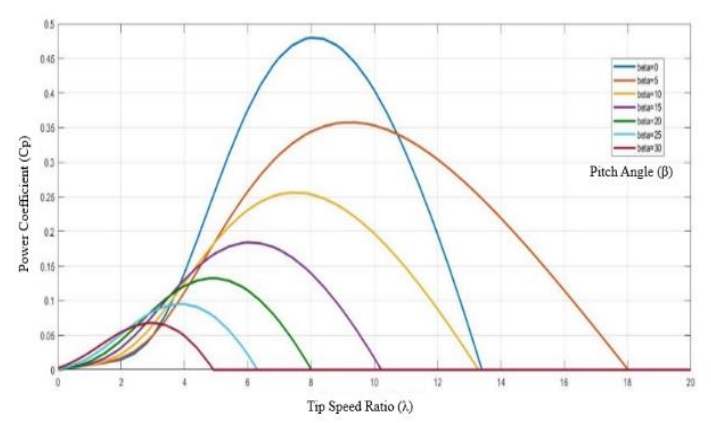

Figure 2. Cp curves as a function of $\lambda$ and $\beta$

According to Figure 2, obtaining the optimum mechanical energy, according to instantly changing wind speed, depends on keeping the power coefficient at the maximum value. Furthermore, keeping the power coefficient at the maximum value for any wind speeds is related to keeping the pitch angle value at the minimum and the tip speed ratio at an appropriate value. As shown in Equation (3), the optimum value of the tip speed ratio can be obtained by adjusting the rotor speed according to the instant wind speed. This adjustment composes the main principle of speed control and MPPT. Another feature shown in Figure 2, the power coefficient is decreased by increasing the value of the pitch angle. This guarantees that excessive power can be limited above the rated wind speeds by adjusting the pitch angle.

\subsection{Generator and drive system model}

Obtaining the mathematical model of a generator is very important to understand which parameters can be used for control. For machines operating at synchronous speeds, the transformation from a 3-phase $(a-b-c)$ stator reference frame to a 2-phase (d-q) reference frame provides convenient control design and analysis as in direct current (DC) machines. This reference frame transformation can be used for the mathematical model of a PMSG and controller designs [2627].

As a result of reference frame transformation, the following equations are used to express the model of the PMSG as shown in Equation (5-6). 


$$
\begin{aligned}
& \frac{d i_{q}}{d t}=\frac{1}{L_{q}}\left[-\left(R_{s} * i_{q}\right)+w_{E}\left(L_{d} i_{d}+\lambda r\right)+V_{q} .\right. \\
& \frac{d i_{d}}{d t}=\frac{1}{L_{d}}\left[-\left(R_{s} * i_{d}\right)+w_{E}\left(L_{q} i_{q}\right)+V_{d} .\right.
\end{aligned}
$$

Where subscripts $d$ and $q$ refer to the physical quantities that have been transformed into the $\mathrm{d}$-q reference frame, $R$ is stator resistance $(\Omega), L_{d}$ and $L_{q}$ are $\mathrm{q}$ and $\mathrm{d}$ axis inductances $(\mathrm{H})$ of the generator, $V_{d, q}$ and $i_{d, q}$ are $\mathrm{d}$ and $\mathrm{q}$ axis voltages. and currents consecutively, $\lambda \mathrm{r}$ is the permanent magnetic flux $w_{E}$, the electrical angular velocity of the generator, as expressed in Equation (7).

$$
w_{E}=\frac{P}{2} \times w_{R} .
$$

Where $P$ is the number of poles of the generator, $w_{R}$ is the mechanical angular velocity of the generator. The electromagnetic torque produced by the generator $\left(T_{E}\right)$ can be expressed based on (d-q) quantities as shown in Equation (8).

$$
\left.T_{E}=\frac{3 p}{2}\left(\left(L_{d}-L_{q}\right) * i_{d} i_{q}\right)+i_{q} * \lambda r\right) .
$$

For a non-salient-pole PMSG, $L_{d}$ and $L_{q}$ inductances are approximately equal. In this case, the equation of electromagnetic torque can be expressed in the following form.

$$
T_{E}=\frac{3 p}{2}\left(i_{q} * \lambda r\right)
$$

In Equation (9), it is seen that the torque equation obtained in the reference frame is similar to the torque equation of DC machines. This similarity proves that reference frame transformation provides ease of control and analysis. Equation (9) also shows that the generator torque can be controlled by the $q$ axis current of the generator [26-28].

The drive system ensuring energy transfer from the turbine to the generator can be treated as a one-lumped mass model. The mathematical model of the drive train presents the motion equation of the system. The equation is defined as in Equation (10).

$$
\frac{d W_{R}}{d t}=\frac{T_{M}-T_{E}}{J}-\frac{B}{J} * W_{R}
$$

Where $J$ is the total moment of inertia, $B$ is the coefficient of viscous friction. $T_{E}$ and $T_{M}$ are electromagnetic and mechanical torques respectively. $W_{R}$ is the mechanical angular velocity of the generator. This equation shows that the rotor speed can be controlled by adjusting the electromagnetic torque. This torque can be adjusted by the q-axis current of the generator based on Equation (8). This adjustment forms the basis of MPPT control for a WECS below the rated wind speeds.

\subsection{Power converter unit}

The main purpose of these units is to produce energy with high efficiency and transfer the produced energy properly. They can also be used as an energy buffer for the power fluctuations caused by the wind turbine and for the transients coming from the load side. There are two common converter types for WECSs. The first configuration is designed as a back-to-back converter connected to the grid or load, the second configuration is a diode-bridge rectifier, a boost converter, and an inverter connected to the grid or load. Designed controllers aim to regulate the operation of the power converter unit for various purposes based on the control variable. For example, adjusting the switching signals in a back-to-back configuration or regulating the duty cycle for a boost converter can be used as control variables for MPPT control [28-31].

\subsection{Pitch angle control}

In this control, the controller, which is activated above the rated wind speeds, provides the opportunity to work at higher wind speeds and mechanical protection [7-8]. Pitch angle control is an essential and useful controller to enhance the efficiency of a WECS and improve the stability of power conversion. Pitch systems are classified into two types, hydraulic and electrical pitch controls. Electrical controls provide more efficient and faster operation [21]. For a PIDbased pitch angle control, different parameters (rotor speed, power, torque, etc.) are compared with their rated values. The error between these values could be used as inputs for pitch angle actuators. Figure 3 shows the working principle of a classical PI controller used for a pitch angle control with various input parameters.

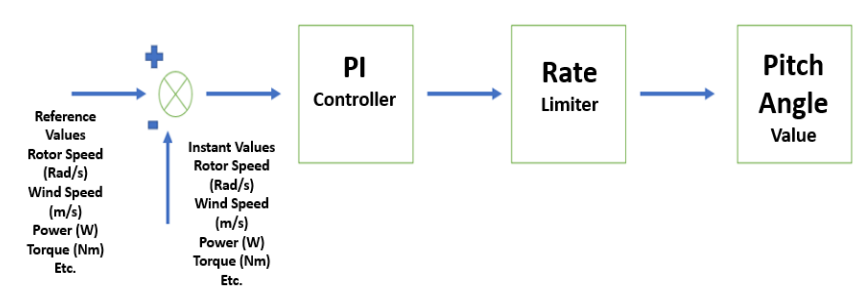

Figure 3. PI controller as a pitch angle control

A rate limiter can be used for adjusting the rate of change of the pitch angle. Furthermore, it adjusts the operating range of the controller. The angle value can also be adjusted to a value that can stop the turbine operation by the used controller in conditions where the wind speed is very high or low $[11,16]$. 


\section{FINDINGS AND DISCUSSION}

Figure 4 shows the general WECS model designed in Matlab/Simulink environment.

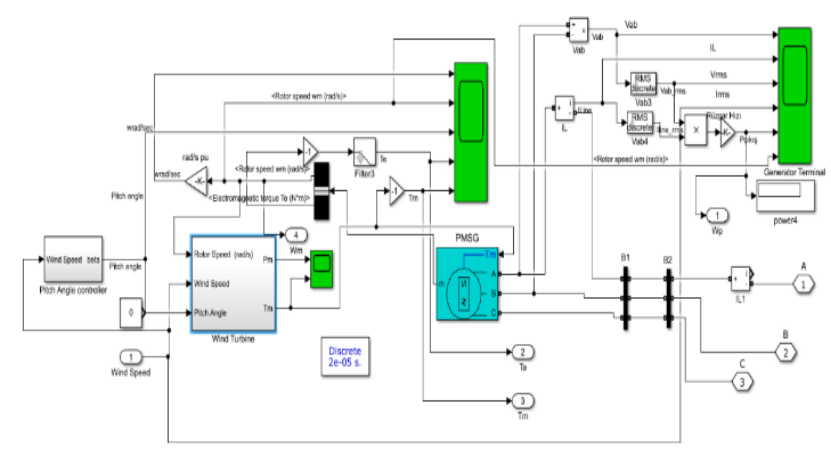

Figure 4. WECS system model

According to Figure 4, the mechanical torque obtained by the turbine is given as input to PMSG by the wind turbine. The mechanical power and torque are obtained based on the mathematical models of the wind turbine. The sign of the torque applied to the PMSG determines whether the machine works as a motor or a generator. The negative torque enables it to work as a generator. The detailed model of the wind turbine is shown in Figure 5.

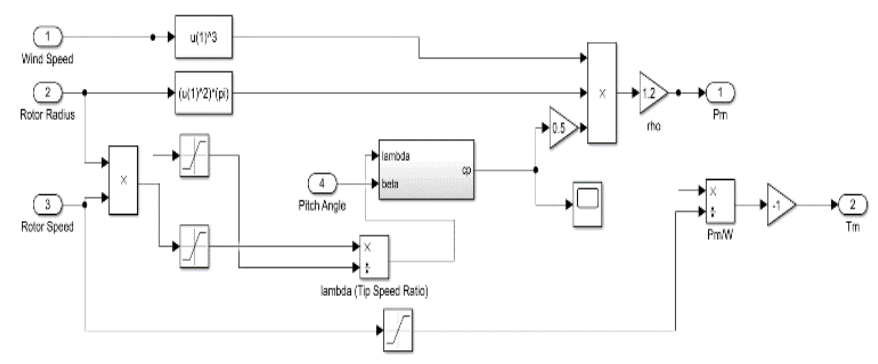

Figure 5. The detailed model of the wind turbine

In the pitch angle control, which is adjusted to activate above the rated wind speed $(12 \mathrm{~m} / \mathrm{s}$ defined in this model). The general system can be operated at the rated values through this control. The Pitch angle is adjusted to change between $0^{\circ}$ $45^{\circ}$. Figure 6 shows the detailed model of the pitch angle control, working based on instant wind speed.

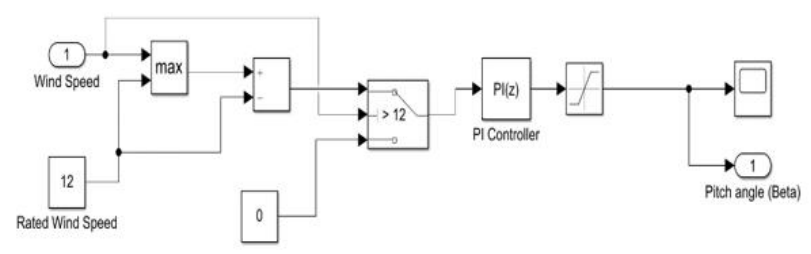

Figure 6. Pitch angle control model

According to the model shown in Figure 6, the control limits the power capturing capacity of WECS to the rated value, if the wind speed is greater than the rated wind speed $(12 \mathrm{~m} / \mathrm{s})$. During lower wind speed, the pitch angle of the turbine is adjusted to the minimum value to rotate the rotor at a higher speed thus increasing the power capacity of the generator.
Control analysis will be carried out for a $1 \mathrm{~kW}$ WECS based on a wind profile as shown in Figure 7.

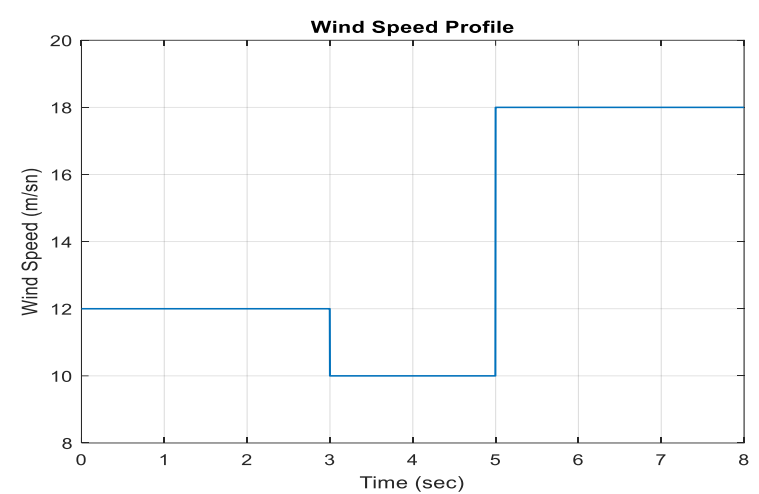

Figure 7. Wind speed profile

When pitch angle control is not applied throughout the simulation period, Figure 8 shows the variation of rotor speed and output power.
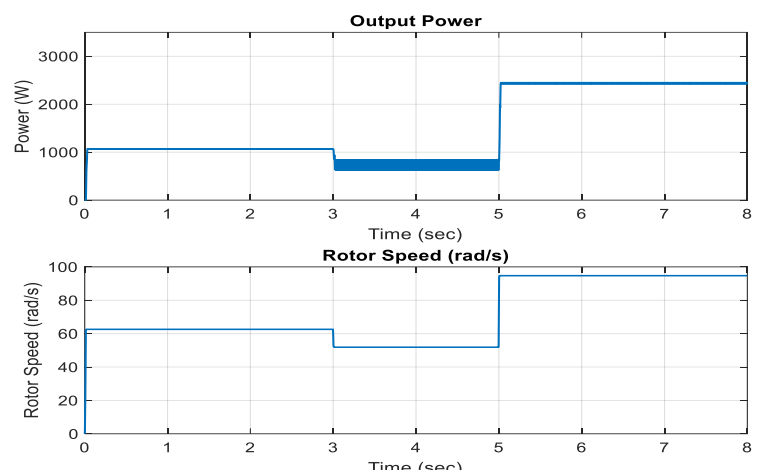

Figure 8. Variation of output power and rotor speed (pitch angle control not applied)

For a $1 \mathrm{~kW}$ system, when the pitch angle control is not applied, the output power increases to a $2.5 \mathrm{~kW}$ level at the fifth second. Power level is higher than the rated value, so this power can damage the system. This problem shows that a pitch angle control is required to limit the output power to the rated value at higher wind speeds.

When the pitch angle control is applied, the angle value starts to increase from the fifth second. Figure 9 shows the variation of the pitch angle.

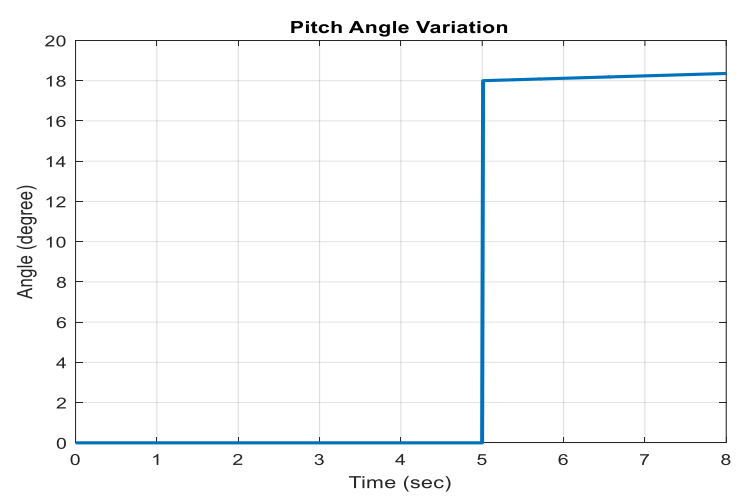

Figure 9. Pitch angle variation

This variation proves that the controller activates only when wind speed above the rated value $(12 \mathrm{~m} / \mathrm{s})$. Figure 10 
shows the variation of rotor speed and output power when the controller is applied.
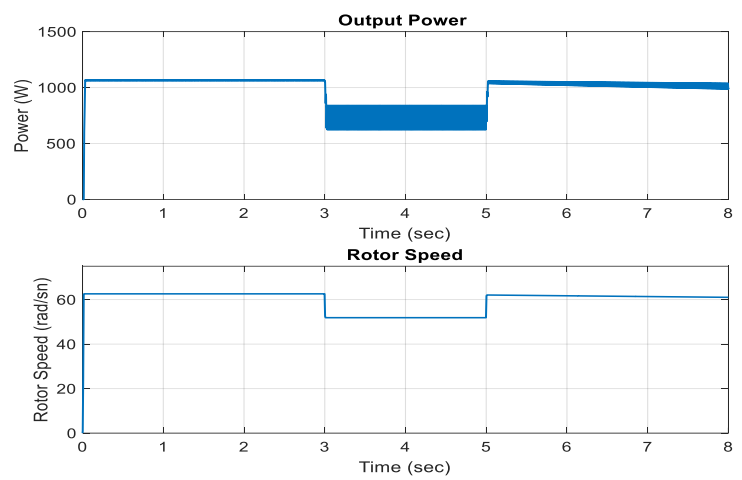

Figure 10. Variation of output power and rotor speed (with pitch angle controller)

The activation of the pitch angle control at the fifth second enables safe energy production at higher wind speeds by limiting the power and rotor speeds to the rated values. This control also enables energy production at higher wind speeds as well as safe operation. Overall efficiency is also improved in this way.

Figure 11 shows the variation of generator output voltage and current according to the pitch angle control
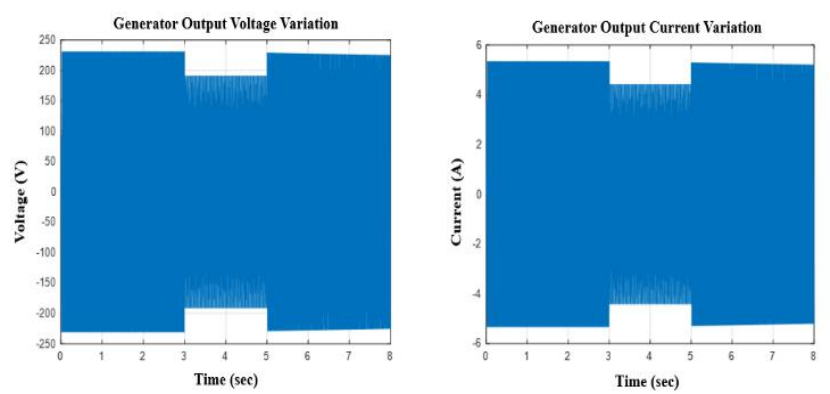

Figure 11. Variation of output voltage and current of the PMSG

When the wind speed exceeds the rated value, the voltage and current values can be limited to the rated values, which indicates that the pitch angle control of the system works properly.

\section{CONCLUSION}

In this study, the working principles of a WECS, mathematical models of the system parameters, and the control methods were explained theoretically. The simulation, conducted in Matlab/Simulink environment, gave detailed information about pitch angle control. Graphical analysis of the system parameters was conducted based on this simulation. It was observed that the system continued to operate without exceeding the rated power at higher wind speeds throughout the simulation period and the output current and voltage remained at the desired value. As used in this study, simulation is an important tool to see the effects of a control structure and make required regulations before the production process. For future studies, instead of PID controller, soft computing techniques such as fuzzy logic, artificial neural networks, and optimization methods can be used for pitch angle control. Simulation studies also allow comparative analysis of different control techniques.

\section{REFERENCES}

[1] Naama, F. Z., Zegaoui A., Benyessad Y., Kessaissia F.Z., Djahbar A., and Aillerie M., "Model and simulation of a wind turbine and its associated permanent magnet synchronous generator", Energy Procedia, vol. 157, no. 2018, pp. 737-745, 2019.

[2] Wang, C.N., Lin W.C., Le X.-K, "Modelling of a PMSG Wind Turbine with Autonomous Control", Math. Probl. Eng., vol. 2014, pp. 1-9, 2014. J. S. Turner, "New directions in communications,” IEEE J. Sel. Areas Commun., vol. 13, no. 1, pp. 11-23, Jan. 1995.

[3] Karakaya, A., Karakaş, E., "Küçük Güçlü Rüzgar Enerji Dönüşüm Sisteminin Benzetimi, Modellemesi ve Uygulamas1, Karaelmas Science and Engineering Journal, pp 377-386, 2016.

[4] Kokate, A., Khandagale, H., George, J., Koli, A., \& Nair, S.Modeling and Simulation of Standalone Wind Energy Conversion System. In 2019 3rd International Conference on Trends in Electronics and Informatics (ICOEI), pp. 1295-1297, 2019.

[5] Kumar, P., Kumar, R., Verma, A., Kala, M.C., "Simulation and Control of WECS with Permanent Magnet Synchronous Generator (PMSG)", in 2016 8th International Conference on Computational Intelligence and Communication Networks (CICN), 2016, pp. 516521.

[6] Vadi, S., Gurbuz, F.B., Bayindir, R., and Hossain E., "Design and Simulation of a Grid-Connected Wind Turbine with Permanent Magnet Synchronous Generator", in 2020 8th International Conference on Smart Grid (icSmartGrid), 2020, pp. 169-175.

[7] Rashid, T. H. M. S, Routh A. K., Rana R., I. Ferdous, and R. Sayed, "A Novel Approach to Maximize Performance and Reliability of PMSG Based Wind Turbine: Bangladesh Perspective American Journal of Engineering Research (AJER)," no. 6, pp. 17-26, 2018

[8] Bhanu Chandra, M. E., "The pitch angle control of variable speed wind turbine using PID controller", International Journal of scientific research and management (IJSRM), vol. 3, no. 11, pp. 3728-3734, 2015.

[9] Chauhan, S., Sameeullah, M, and Dahiya, R. "Maximum power point tracking scheme for variable speed wind generator", in 2014 IEEE 6th India International Conference on Power Electronics (IICPE), 2014, pp. 1-5.

[10] Mohd, M., Shadab, A. and Mallick, M. "Simulation and Control of 20 kW Grid Connected Wind System”, International Journal of Electrical and Electronics Engineering Research (IJEEER)., vol. 3, no. 3, pp. 275-284, 2013.

[11] Biswal, G.S., Mohapatra, A., "A Grid Integrated PMSG Using Wind Energy Conversion System with Various Pitch Angle", International Journal of Innovative Research in Science, Engineering and Technology, pp. 5101-5109, 2018.

[12] Devashish, Thakur, A., "A comprehensive review on wind energy system for electric power generation: Current situation and improved technologies to realize future development", Int. J. Renew. Energy Res., vol. 7, no. 4, pp. 1787-1805, 2017.

[13] Tiwari, R., and R. B. N, "Comparative Analysis of Pitch Angle Controller Strategies for PMSG Based Wind Energy Conversion System," Int. J. Intell. Syst. Appl., vol. 9, no. 5, pp. 62-73, May 2017

[14] Slah, H., Mehdi, D. and Lassaad, S., "Advanced Control of a PMSG Wind Turbine", Int. J. Mod. Nonlinear Theory Appl., vol. 05, no. 01, pp. 1-10, 2016.

[15] Hassan, S.Z., Li, H., Kamal, T., Abbas, M.Q, Khan, M.A. and Mufti G.M., "An intelligent pitch angle control of wind turbine", in 2017 International Symposium on Recent Advances in Electrical Engineering, RAEE 2017, 2017, vol. 2018, pp. 1-6.

[16] Van, T.L., Nguyen, T.H. and Lee, D.C., "Advanced Pitch Angle Control Based on Fuzzy Logic for Variable-Speed Wind Turbine Systems", IEEE Trans. Energy Convers., vol. 30, no. 2, pp. 578-587, 2015

[17] Yilmaz, A.S., Özer, Z., "Pitch angle control in wind turbines above the rated wind speed by multi-layer perceptron and radial basis function neural networks," Expert Syst. Appl., vol. 36, no. 6, pp. 9767-9775. 2009.

[18] Civelek, Z., Çam, E., Lüy, M., \& Görel, G., "A new fuzzy controller for adjusting of the pitch angle of the wind turbine.", The Online Journal of Science and Technology, vol. 6, no 3,2016.

[19] B. Wu, Y. Lang, N. Zargari, and S. Kouro, Power Conversion and Control of Wind Energy Systems. John Wiley \& Sons, Inc., New York, 2011.

[20] Anaya Lara, O., Jenkins, N., and Ekanayake, J, Wind Energy Generation Systems: Modelling and Control, John Wiley \& Sons., New York, 2011 
[21] Tiwari, R., Babu, N.R., "Recent developments of control strategies for wind energy conversion system," Renew. Sustain. Energy Rev., vol. 66, pp. 268-285, 2016

[22] Yin, M., Li, G., Zhou, M and Zhao, C., "Modeling of the Wind Turbine with a Permanent Magnet Synchronous Generator for Integration", in 2007 IEEE Power Engineering Society General Meeting, pp . 1-6, 2007

[23] Gajewski, P., Pieńkowski, K., "Advanced control of direct-driven PMSG generator in wind turbine system," Arch. Electr. Eng., vol. 65, no. 4, pp. 643-656, 2016.

[24] Rolan, A., Luna, G., Vazquez, D., Aguilar, and Azevedo, G., "Modeling of a variable speed wind turbine with a Permanent Magnet Synchronous Generator", in 2009 IEEE International Symposium on Industrial Electronics, pp. 734-739, 2009

[25] Priya, G. J.," Modelling and performance analysis of grid-connected PMSG based wind turbine.", International Journal of Advanced Research in Electrical, Electronics and Instrumentation Engineering, 3(2), pp 155-165, 2014

[26] Patil K., Mehta, B. "Modeling and simulation of variable speed wind turbine with direct drive permanent magnet synchronous generator", in 2014 International Conference on Green Computing Communication and Electrical Engineering (ICGCCEE), pp. 1-6, 2014.

[27] Gencer, A., "Modelling of operation PMSG based on fuzzy logic control under different load conditions", in 2017 10th International Symposium on Advanced Topics in Electrical Engineering (ATEE), 2017, pp. 736-739

[28] Ackermann, T., Wind Power in Power Systems, John Wiley \& Sons, Chichester, UK, 2005.

[29] Hussein, M. M., Orabi, M., Ahmed, M. E., Sayed, M. A., "Simple sensorless control technique of permanent magnet synchronous generator wind turbine," PECon2010 - 2010 IEEE Int. Conf. Power Energy, pp. 512-517, 2010

[30] Jafari, H. K. . "Effect of Turbulence on Fixed-Speed Wind Generators", Advances in Wind Power, 31,2012.

[31] Yaramasu, V., Wu, B., Sen, P. C., Kouro, S. and Narimani, M., "Highpower wind energy conversion systems: State-of-the-art and emerging technologies," Proc. IEEE, vol. 103, no. 5, pp. 740-788, 2015.

\section{BIOGRAPHIES}

Hasan Bektas Percin obtained his BSc degree in electrical and electronics engineering from Firat University in 2011. He has been studying on MSc degree in electrical and electronics engineering at Firat University. His research interests are renewable energy, energy efficiency, smart control modelling.

Abuzer Caliskan obtained his BSc degree in electrical and electronics engineering from Firat University in 1997. He received the MSc., and PhD. diploma in Electrical and Electronics Engineering from the Firat University in 2004 and 2011 respectively. His research interests are power elctronics drive circuits, electric machines, renewable energy, energy efficiency and their modeling. In 2002 he joined the Faculty of Electrical and Electronics Faculty, Firat University as a research assistant, where he is presently working as an assistant professor. 